\title{
LEGISLAÇÃO DE ENSINO E FORMAÇÃO INICIAL DE PROFESSORES: MOMENTOS DE REFLEXÃO SÓCIO-EDUCACIONAL E POLÍTICA NO AMBIENTE DA CIDADE DE COARI NO MÉDIO RIO SOLIMÕES.
}

\author{
Ademar Vieira dos Santos ${ }^{1}$ \\ Eliana Rodrigues Tiago ${ }^{2}$ \\ Francisco César Brito Vieira ${ }^{3}$ \\ Doriedson Oliveira dos Santos ${ }^{4}$
}

\section{Resumo}

Este relato de experiência é resultado de atividades realizadas como professor de Legislação de Ensino Básico com estudantes do curso de Licenciatura em Matemática e Física do Pólo de Saúde e Biotecnologia da Universidade Federal do Amazonas no Médio Rio Solimões. O objetivo do curso foi de através dos conteúdos inicialmente planejados, e das estratégias de aprendizagem desenvolvidas em sala de aula, possibilitar aos estudantes entender que a legislação de ensino no Brasil é resultado do processo histórico que ao longo da história vem se desenvolvendo. Como metodologia de trabalho houve a necessidade da utilização de questionários com questões abertas onde os aprendizes tiveram a oportunidade de explicitar sobre a concepção que possuíam sobre legislação antes e após o curso. Como resultado foi possível constatar

\footnotetext{
${ }^{1}$ É professor mestre formado pela universidade de Lion, Espanha, e atualmente é professor da Universidade Federal do Amazonas - UFAM, no pólo de Saude e Biotecnologia de Coari Rio Solimões. Email <santos.2007@uol.com.br>

2 É psicóloga e mestre formada pela universidade Federal do Amazonas, atualmente é professora da Universidade Federal do Amazonas - UFAM, no pólo de Saude e Biotecnologia no município de Coari Rio Solimões.

${ }^{3}$ Licenciado em Normal Superior e Mestrando do Programa de Pós Graduação e Ensino de Ciências na Amazônia, pela Universidade do Estado do Amazonas - UEA. E-mail <missoesbrito@yahoo.com.br> ${ }^{4}$ Licenciado em Pedagogia pela Universidade do Estado do Amazonas - UEA e Pós-Graduado em Metodologia do Ensino Superior, pela Universidade Gama Filho, Manaus-AM.
} 
que antes a maioria dos estudantes não possuía nenhum conhecimento sobre legislação. Para alguns, legislação de ensino é coisa de especialista, ou apenas um conjunto de regras para serem devidamente cumpridas. Após a realização da disciplina, um grande número já concebe a legislação como um processo resultante do contexto histórico. Outros afirmam que através do conhecimento da legislação podem conquistar sua cidadania, que agora já podem entender melhor os seus direitos e deveres. Este estudo é relevante pela possibilidade que tem de oferecer referência a estudantes, professores ou pesquisadores que queiram aventurar-se numa maior compreensão da Legislação de Ensino no Brasil

Palavras-Chave: Amazônia, Formação e Legislação

\section{Introdução}

O interesse por esse estudo surgiu da experiência como professor de Estrutura do Ensino Básico com estudantes de licenciatura do Curso de Matemática e Física da Universidade Federal do Amazonas no Pólo de Saúde e Biotecnologia de Coari no Médio Rio Solimões.

Através da disciplina tínhamos o objetivo de proporcionar aos estudantes uma maior compreensão dos fundamentos da estrutura e funcionamento da Educação Básica, da política educacional do país e seus sistemas de ensino.

Para isto procuramos mostrar para os estudantes que a legislação de ensino no Brasil é resultado do processo socioeconômico e político vivenciado nas diferentes épocas da história do país.

Para que os aprendizes tivessem mais liberdade para expor as suas concepções sobre o assunto utilizamos questionário com questões abertas visto que [...] são as que permitem ao informante responder livremente, usando linguagem própria, e emitir opiniões. (MARCONI e LAKATOS, 2003, p. 204). E também a observação participante 
que "consiste na participação real do pesquisador com a comunidade ou grupo, onde ele se incorpora ao grupo e confunde-se com ele. Fica tão próximo quanto um membro do grupo que está estudando e participa das atividades normais destes" (MARCONI \& LAKATOS 2009, p. 196).

$\mathrm{Na}$ primeira pergunta procurou-se investigar dos estudantes, a concepção que eles possuíam sobre legislação antes de iniciar a disciplina. Na segunda procuramos saber a concepção que passaram a ter após o término da mesma.

Com base nos questionários, após a tabulação dos dados elaboramos as categorias de análise reflexivas sobre as respostas dos estudantes.

\section{Concepção sobre legislação de ensino na formação inicial de professores de física e matemática}

Cinqüenta por cento dos estudantes não possuíam nenhum conhecimento sobre legislação de ensino.

Para os demais:

> Não era um assunto importante;

Aula de legislação era coisa de especialista;

D As leis eram feitas para beneficiar alguém;

> Era um conjunto de regras feitas para serem cumpridas, e não podiam ser criticadas.

A legislação de ensino no Brasil, de certo modo é o resultado das relações econômicas, políticas e culturais construídas desde épocas bem remotas na história da civilização ocidental, um processo que vem se reconfigurando diante dos novos contextos do capitalismo globalizado. 
Não somente na educação, porém de modo geral é possível constatar que as leis que foram inicialmente criadas ainda no Brasil Colônia, eram realizadas com o propósito de beneficiar a burguesia européia ou brasileira. Diante disso eram leis feitas sem a participação das classes populares, por esse motivo elas nunca se interessaram em discutir ou participar do processo legislativo, apenas de forma alienada elegem alguém para delegar isso por elas.

Diante dessas práticas, a cultura e a concepção sobre legislação disseminada no interior das colônias e posteriormente países independentes e em desenvolvimento tem sido de que as pessoas responsáveis por criar as leis são seres iluminados, superiores, capazes de pensar leis que dêem conta dos direitos de todos os outros mortais, que estes por sua vez não precisam ter nenhum conhecimento sobre tal.

Diante dessa concepção, historicamente legislação se tornou um assunto sem muita importância para a maioria das pessoas nas comunidades, nas pequenas e até grandes cidades da Amazônia. Que preferem esperar que os "especialistas" criem e aprovem políticas públicas que atendam as demandas sócio-educacionais e econômicas de todas elas. Para elas, é mais cômodo esperar pela boa vontade dos legisladores.

Essa cultura se reproduziu e ganhou muita força em diferentes períodos da política brasileira, entre os quais, o regime militar, durante o qual a sociedade perdeu totalmente o direito de participar através do voto da escolha dos candidatos aos cargos majoritários do país. "Nossos sentimentos, nossas condutas, nossas ações e nossos comportamentos são modelados pelas condições em que vivemos (família, classe e grupo sociais, escola, religião, trabalho, circunstâncias políticas)" (CHAUI 2003, p.311).

Toda legislação acontecia em forma de decreto, delegada pelos generais que se revezavam no poder, sem a menor participação da sociedade civil.

Essa prática retroalimenta a concepção que a sociedade vinha construindo durante o Brasil Colônia, Império e República Velha, de que a legislação é um conjunto de regras, feitas por autoridades intocáveis. Que os demais sujeitos devem apenas fazer-las cumprir, não importa as circunstâncias em que tais leis tenham sido criadas e aprovadas. 
No interior da Amazônia, pelo tipo de colonização colocada em prática pelos europeus e pela burguesia econômica brasileira, como também as longas distâncias dos grandes centros e a precariedade na chegada das informações, a concentração de poderes nas mãos dos grandes latifundiários, (seringalistas ou coronéis de barranco), o atraso no desenvolvimento do processo educacional, e outros fatores, fizeram com que as concepções conservadoras sobre legislação e política fossem sendo erradicada de forma tardia e muito lenta.

\section{Concepção dos estudantes sobre legislação de ensino após concluírem a disciplina: perspectivas de mudanças no ambiente sócio-educacional e sócio-ambiental.}

Oitenta por cento dos estudantes passaram a perceber que;

D A legislação é importante no contexto da sociedade;

$>$ Que podem defender os seus direitos;

> Tem profundo impacto no desenvolvimento;

Conhecer a legislação faz parte da cidadania.

Os demais dizem que agora possuem certo conhecimento sobre legislação.

Os estudantes demonstram que passaram a perceber que a legislação é de fundamental importância na estruturação e organização do sistema educacional e da sociedade, que só através dela os sujeitos podem vislumbrar perspectivas de cidadania.

A legislação é uma forma de apropriar-se da realidade política por meio das regras declaradas, tornadas públicas, que regem a convivência social de modo a suscitar o sentimento e a ação da cidadania. Não se apropriar das leis é, de certo modo, uma renúncia à autonomia e a um dos atos constitutivos da cidadania (CURY 2000, p. 13) 
Percebe-se certa curiosidade por parte dos estudantes, visto que somente após cursar a disciplina descobriram que possuíam direitos, e que agora podem se apropriar de tais.

Acreditamos ser um momento de extrema importância na vida desses aprendizes, considerando a possibilidade que têm de construírem sua contra hegemonia, iniciando dessa forma o rompimento mesmo que de forma tardia e gradativa de séculos de marginalidade vivenciada por seus ancestrais. Numa terra totalmente sem lei, onde tudo funcionava a partir das determinações dos seringalistas, dos regatões. "A marginalidade cultural, os conflitos inevitáveis, as angústias das distâncias, do isolamento geográfico e social decorrente também de certas injustiças, de certas ambigüidades de leis" (ARAUJO 2003, p. 151).

O conhecimento da legislação de ensino torna-se significativo a partir do momento que os próprios estudantes se percebem como sujeitos capazes de dar sentidos as suas vidas, acreditando que podem lutar por políticas públicas impactantes que viabilizem qualidade de vida para as comunidades. Eles começam a acreditar na aplicabilidade e veracidade das leis, que de alguma forma eles podem sair do papel e se tornarem reais.

O mundo percebido é qualitativo, significativo, estruturado e estamos nele como sujeitos ativos, isto é, damos as coisas percebidas novos sentidos e novos valores, pois as coisas fazem parte de nossas vidas e nós interagimos com o mundo (CHAUI 2003, p. 135).

Essa trajetória de interação não pode acontecer de imediato, ela é construída de acordo com a forma como os sujeitos protagonistas do meio amazônico vão criando possibilidade para a realização de alguns movimentos sociais, sem os quais não poderão almejar a conquista do desenvolvimento sustentável ou da cidadania.

Pela motivação demonstrada pelos futuros professores durante a disciplina e nas respostas dos questionários, percebe-se que eles têm sonhos e muita força de vontade em relação à politização e transformação social das comunidades no interior da 
Amazônia onde vivem. "Os professores, por mais que pareça estranho, são pessoas que sentem e querem... não só pensam" (SACRISTÃN 2002 p.86).

Isto é de extrema relevância por nos potencializar a entender que de alguma forma os estudantes já estão construindo bases do processo de transformação e cidadania que tanto pretendem.

\section{CONSIDERAÇÕES FINAIS}

De acordo com o tema desenvolvido, com os objetivos da disciplina, dos questionários e de seus objetivos, acreditamos que os resultados foram de extrema importância, por revelar que os estudantes conseguiram entender a Legislação de Ensino, não como uma simples disciplina obrigatória do currículo escolar, ou como uma reprodução de conteúdos de Legislação de Ensino.

Porém como conjunto de leis resultante do contexto histórico econômico e político que vêm se configurando desde a Revolução Industrial.

Eles passaram a entender que se trata de um processo histórico, que as suas práticas e os seus projetos políticos, ou a Legislação de Ensino também devem ser históricos, devem ser construídos com base na realidade econômica e política das comunidades amazônicas.

Eles começam a perceber que têm responsabilidade na fiscalização das leis elaboradas, votadas e aprovadas nas câmaras municipais dos municípios onde vivem e atém em âmbito nacional.

Portanto, foi possível perceber que aqueles aprendizes passam a se sentir sujeitos do processo político da nação, acreditando até que podem influenciar de alguma forma na aprovação e reprovação das leis do País. 


\section{REFERÊNCIAS}

ARAUJO, André Vidal. Introdução à Sociologia da Amazônia. Manaus: Editora Valer 2003.

CHAUI, Marilena. Convite a Filosofia. São Paulo: Editora Ática 2003.

CURY, Carlos Roberto Jamil. Origem Etimológica, Educação e Constituição. Legislação educacional brasileira. Rio de Janeiro: DP\&A, 2000.

Leis Nacionais da Educação: Uma Conversa Antiga. CURY, Carlos Roberto Jamil et. ali. Medo à Liberdade e Compromisso Democrático: LDB e Plano Nacional da Educação. São Paulo: Editora do Brasil, 1997.

SACRISTÃ, José Gimeno. Tendências Investigativas na formação de professores. In: PIMENTA, Selma Garrido e GHEDIN, Evandro. Professor reflexivo no Brasil. Gênese e critica de um conceito. São Paulo: Editora Cortez 2002. 